\title{
An analysis of note-taking strategies: The effect of translanguaging on content comprehension and knowledge retention
}

\author{
Xinyi Wang \\ The University of Oxford, Oxford, United Kingdom
}

Received: November 1, 2021 / Accepted: November 16, 2021 / Published Online: November 29, 2021

(c) Pioneer Publications LTD 2021

\begin{abstract}
Purpose This study investigates the effectiveness of using translanguaging for note-taking on students' lecture comprehension and retention by measuring their scores on two tests administered two weeks apart. Methods The participants were English L2 Chinese graduate students $(\mathrm{n}=101)$ studying in English-language programs in various English-speaking countries at the time of the study. The study used a quasi-experimental three-arm parallel groups design to compare the relative effects of three alternative approaches to note-taking (Chinese, English, and translanguaging). All participants watched a five-minute English-language video without subtitles and took notes using their assigned strategies. Then participants immediately took a comprehension test. After two weeks, participants took a retention test. Results The results showed that those taking notes in English only outperformed those taking notes using Chinese only on low-level, fact-based questions in the comprehension test. There was no significant difference found among the three language groups (Chinese, English, and translanguaging) in other types of questions (main topic questions and numerical questions) and the overall score. In the retention test, those taking notes in English outperformed those taking notes in Chinese in the overall score and all question types except for number-based questions, with the translanguaging groups also outperforming the Chinese group in fact-based questions. In addition, students' previous study abroad experience was not found to impact students' comprehension and retention of the video lecture content. Conclusion It seems that translanguaging does not aid advanced L2 learners in immersion contexts; instead, translanguaging may be more helpful for lower proficiency L2 learners.
\end{abstract}

Keywords translanguaging; note-taking strategies; knowledge retention; cognitive load theory; bilingualism

\section{Introduction}

The discussion of using one's first language (L1) in a second language (L2) classroom, such as in bilingual or immersion programs, is controversial. Some researchers have claimed that using L1 in an L2 immersion setting can negatively impact the development of L2. LaVan (2001) noticed that with more English used in Spanish conversation, students started to produce "Spanglish", and the accuracy of Spanish usage decreased. Furthermore, some immigrant parents do not want their children to learn their language, but instead prefer their new country's main language to be the children's native one (Jacobs, 1998; Brown, 2011; Goodwin, 2002).

Translanguaging is one of the possible ways to implement this kind of instruction, as it allows multiple languages to co-exist in learning. However, Siegel (2020) has claimed there is lack of empirical research on translanguaging in academic writing. Also, Lewis et al. (2012) and Duarte (2020) argued translanguaging research lacks empirical evaluation of educational outcomes. In his previous research of English for Academic Purpose (EAP) students' notes, Siegel (2016, 2018) found that the students used a combination of $L 1$ and L2 in their notes. Thus, he concludes that the application of translanguaging should be expanded to notetaking, which can be considered as a type of academic writing. He argues that translanguaging in note-taking allows students to use all linguistic resource available to them, potentially making it a more effective way to take notes than staying in a single language (Siegel, 2020). In addition, some translanguaging guides for educators provided translanguaging writing activities, and claimed those activities would benefits students in writing without empirical evidence (Hesson et al., 2014; Celic \& Seltzer, 2011). The current study will contribute to the literature by addressing the lack of empirical studies on translanguaging in pedagogy. The aim in this 
dissertation is to investigate the effectiveness of using translanguaging in writing through comparing students' comprehension and retention of lecture content by note-taking in their L1, L2 or combination of L1 and L2.

Researchers have claimed that translanguaging as an approach is lacking in the empirical evaluation of its effectiveness on classroom strategies and educational outcomes (Lewis et al., 2012; Conteh, 2018; Duarte, 2020); thus, the current study aims to fill this gap. One of the specific goals of the study is to investigate the educational effects of using translanguaging in notetaking. Chalmers (2019) and Hopp et al. (2021) found that a translanguaging approach did not boost or hinder students' vocabulary knowledge and foreign language development. However, a translanguaging guide for educators wrote by Hesson et al. (2014, p. 4) clearly stated that "All students would benefit from the translanguaging instructional contexts and strategies offered." In addition, my study also investigates whether students' study abroad experience has an impact on students' educational outcomes.

\section{Literature Review}

\subsection{Bilingualism}

Definitions of bilingualism "range from a nativelike competence in two languages to a minimal proficiency in a second language" (Hamers et al., 2000, p. 7). According to Cummins (1980), people have had misinterpretations about how bilingualism works in the brain. The misconception hinged on the assumption that there was limited linguistic capacity for each person; thus, it was assumed bilingual speakers would have language deficiencies compared to monolingual speakers.

In response to these ideas, Cummins (1980) established a model called Common Underlying Proficiency (CUP) to illustrate the way languages operate in the bilingual brain. It imagines linguistic competence as a single balloon with two channels attached to it. (Cummins, 1980). One channel represents L1 linguistic development; the other, L2 linguistic development. The underlying language proficiency from both languages are shared in one balloon, meaning that L1 literacy ability, for example, can support L2 literacy development. In addition, Cognitive/Academic Language Proficiency (CALP) refers to the skills that people use in real and informal academic settings (Cummins, 1980). CALP is essential to bilinguals' language development because elements of CALP learned through either L1 or L2 do not need to be re-learned in the other language. Cummins (2001) provides an example to support this idea. Students who learned to tell the time in their first language also acquire the concept of telling time in any of their languages. When they need to tell time in their second language, they do not need to re-learn the concept of telling time, instead "they simply need to acquire new labels, or 'surface structures,' for an intellectual skill they have already learned” (Cummins, 2001, p.18). This mutually supportive relationship between L1 and L2 is called the "Linguistic Interdependence Hypothesis" (Cummins, 1979). Cummins (1981) further defined the linguistic interdependence hypothesis as the fact that increased proficiency in L1 can lead to increased proficiency in L2, provided that learners have adequate exposure to L2. Furthermore, in both bilingual and immersion programs, both minority and majority students benefit in their language abilities from minority language instruction (Cummins, 1981). In sum, Cummins's theory argues that the development of two languages in a bilingual brain are mutually supportive of each other.

\subsection{Cognitive load theory}

Cognitive Load Theory, a framework introduced by Sweller (1988) to explain the difficulties encountered generally in problem solving as a task. Chandler and Sweller (1991, p. 294) provided a simple definition: "Cognitive load theory is concerned with the manner in which cognitive resources are focused and used during learning and problem solving." Cooper (1998, p. 11) also describe Cognitive Load Theory, and refer to it as "the total amount of mental activity imposed [by various tasks] on working memory at an instance in time." In general, working (or short-term) memory is limited both in capacity and time when encountering new information (Sweller, 2005). However, long-term memory's capacity is huge (Sweller, 2005) and information can generally be retrieved when needed (Sweller et al., 1998). In the realm of learning, Cognitive Load Theory becomes relevant when trying to understand how best to move information from working memory to long-term memory without overloading the cognitive system. The next section illustrates examples of how using L1 in an L2 classroom environment can lighten the cognitive loads on students.

\subsection{Cognitive load in note-taking}

The advantages of taking notes in academic lectures have been supported by much research (Williams et al., 2013; Hartley, 2002; Suritsky \& Hughes, 1991; Laidlaw et al., 1993; Kiewra et al., 1995). Taking notes can enhance individuals' memory and retention and can lead to a deeper understanding of the information (Sakurai, 2018; Kiewra, 1987). Notes also act as an additional resource for individuals to use in preparing for exams and reviewing concepts (Sakurai, 2018). However, taking notes while understanding the lecture at the same time is not an easy task, even when in a completely monolingual environment, and the quality of notes can decrease due to the distraction of comprehending lecture content (Clark et al., 2013). According to Piolat et al. (2005), note-taking is always under the time pressure of the lecturer's speech rate; speech speed is around 2 to 3 words per second, but writing speed is around only 0.2 to 0.3 words per second (Piolat et al.,2005). Thus, we can assume that note-taking is harder for students when lecture is in their L2 and taking notes in their L2 rather than their L1, simply because of the higher cognitive load necessitated (Piolat 
et al., 2008).

Some researchers have taken interest in how taking notes in one's L1 or one's L2 influences educational outcomes (Park, 2019; Tsai-Fu et al., 2010; Siegel, 2020); however, there are no previous studies on using a combination of languages to take notes. Tsai-Fu et al. (2010) conducted a study to investigate the differences in comprehension of English-language short conversations and long lectures between college students who took notes in their native Mandarin or non-native English. The results showed that note-taking languages affected students' comprehension of both the short conversation and long lecture; specifically, taking notes in English seemed to allow students to capture more content and do better on the test.

In contrast, Park (2019) found different results from Tsai-Fu et al.'s (2010) study. This study also aimed to look at the differences in lecture comprehension and note quality between groups taking notes in L1 or L2. The participants were college-age native Korean speakers who spoke English as an L2 and were taking English medium instruction (EMI) college courses. Both groups watched two 12-minute lectures and took notes at the same time. After each video, they reviewed their notes, and took a 10-minute comprehension test. The results show that there was no significant difference between the comprehension level and note quality based on different note-taking languages, which contradicts Tsai-Fu et al.'s (2010) study. One possible reason is that all participants in Tsai-Fu et al.'s (2010) are college students majoring in English, which may have made their English skills more advanced than those of the participants in Park's study (2019), whose participants were from various majors that may not always require high English proficiency. This explanation would fall in line with the prediction in section 2.4.1 that advanced L 2 speakers might perform better in their L2 than in their L1 when taking notes in L2 lecture.

\subsection{Translanguaging theory}

The term translanguaging was calqued from the Welsh term trawsieithu by Williams (1994), who viewed it as "a pedagogical practice where students are asked to alternate languages for the purposes of receptive or productive use" (García \& Wei, 2014, p. 20). For instance, in Williams' case, Welsh-English bilingual teachers might use English textbooks and language to instruct the class, students can read in English as an input, but they are asked to use Welsh as an output (writing short paragraphs or summaries in Welsh) and vice versa (Vaish, 2020). A more current definition of translanguaging in pedagogy is "the act performed by bilinguals of accessing different linguistic features or various modes of what are described as autonomous languages, in order to maximize communicative potential" (García, 2009, p. 140). In addition, it has been used as a more recent conceptualization of bilingualism (García, 2009); however, translanguaging goes beyond the idea of bilingualism in pedagogy, as it "is a more encompassing and transformative concept than bilingualism" (García \& Wei, 2014, p. 70). First, bilingual education is often wary of the usage of each language contexts, whether they be classrooms, communities, or nation-states. However, nowadays, the boundary of specific language use in specific communities has been weakened, and the world has more diverse and dynamic human interaction than ever before.

As translanguaging has become more popular, it has been applied mostly to migrant and minority languages in pedagogical settings in order to advocate for linguistic minorities (Cenoz, 2017), to better understand lesson content (Creese \& Blackledge, 2010), and to improve literacy ability (Hornberger \& Link, 2012) and overall language learning (Mary \& Young, 2017). However, Duarte (2020) reported that there is lack of research focused on translanguaging's actual influence on educational outcomes, which is also supported by Lewis et al. (2012) and Conteh (2018). Beyond this, some educators have claimed that translanguaging lacks a clear definition and it is too idealistic to apply to a classroom (Ticheloven, 2016, as cited in Duarte, 2020). However, Duarte (2020) and Günther-van der Meij et al. (2020) observed multiple translanguaging classrooms, evaluating the various functions of translanguaging across the programs and the goals they achieved.

In addition, Günther-van der Meij et al. (2020) and Duarte (2020) showed the functions that translanguaging has and what goals it can achieve in a natural pedagogical setting. These include anything from supporting minority students' identities to increasing comprehension of the content. However, while the functions of translanguaging are admirable, its effectiveness on academic outcomes still needs to be explored further, as there have only been qualitative claims of academic improvement by students in a translanguaging program.

\section{Methodology}

\subsection{Research questions}

The current empirical studies claim that using translanguaging is helpful to students' writing skills, but these studies did not empirically test the effect of translanguaging approaches on educational outcomes. As Siegel (2020) suggested, future research should investigate translanguaging in note-taking, and the current study aims to do just that. This study aims to investigate the difference in comprehension and retention of L2 lecture information based on using translanguaging or a single language (L1 or L2) to take notes. In other words, will students perform better when they use all their linguistic resources compared to when they use only one linguistic resource? In addition, this study also aims to investigate how students' undergraduate study experience affects their comprehension and retention ability of English lecture. The research questions guiding these aims are as follows:

1. What are the relative effects of Chinese university students using Chinese, English, or their choice of Chinese and/or English (translanguaging) to take notes while listening to a short video lecture on: a) 
comprehension of the lecture content; b) retention of the knowledge; and c) the quality of the notes?

2. Are the scores of comprehension and retention tests affected by students' undergraduate experience in study abroad?

\subsection{Research hypotheses}

\section{RQ1 predictions:}

If taking notes in Chinese is the most effective language, it means using L1 to take notes requires students to use much cognitive load in understanding, translating, and paraphrasing the lecture content. This process makes students encode the knowledge well in their memory.

If taking notes in English is the most effective language, it means transcribing (listening L2 and write notes down in L2) use little cognitive load. Students can use more cognitive load on listening and comprehension of the lecture material.

If taking notes in translanguaging is the most effective way, it means the least cognitive load is used when students have all linguistic resources available to them instead of stick to one language.

\section{$R Q 2$ predictions:}

Students who studied both abroad and in China should outperform the other two groups in both the comprehension and retention tests because they have the experience in taking notes in both L1 and L2 in college.

\subsection{Research design: quasi-experimental ap- proach}

A quasi-experimental design (Gopalan et al., 2020) was used for several reasons. Firstly, the self-selection of the participants as volunteers and the snowballing recruitment methods make it impossible to fully randomize those who joined. Participants were recruited through social media by using the snowballing method (see Appendix A), where some subjects who agreed to participate the study later invited their acquaintances to be participants as well. Also, some of subjects shared the advertisement for the study to their social media account in order to recruit more people to participate. It was also impossible to blind participants to the intervention they were assigned, as they needed to know with which language(s) they were assigned to take notes. Lastly, the participants were only quasi-randomly assigned to their specific interventions, English Only Group, Chinese Only Group, and Translanguaging Group.

\subsection{Participants}

Fifty-seven potential participants' information was collected through a language background questionnaire (See Table 3.1, 3.2, \& 3.3). The population of focus was L2 English/ L1 Chinese graduate students who were studying in an English-speaking country using English as a medium of instruction at the time of the study. Of this population, only participants in graduate programs in the UK, US, and Singapore were sampled due to affiliation with the author. All had begun learning English formally by at least 10 years of age. Participants were selected based on their linguistic and educational background. First, all participants attended middle school, primary school, and kindergarten in China. This ensured all participants have proficiency in Chinese literacy skills, making them able to take notes in Chinese. Second, all participants had an undergraduate degree earned in various programs, conducted in China, in English-speaking countries, or in both. Lastly, they had to be studying in an English-language graduate program at the time of the study, which was taken to indicate English language skills sufficient to take notes and understand the content of the video. The detailed information of the participants who actually completed the entire experiment will be presented as a part of the questionnaire results in Chapter 4 (see Figure 4.1).

Table 3.1. Participant's language instruction background

\begin{tabular}{|c|c|c|c|c|c|c|c|}
\hline $\begin{array}{c}\text { Number of } \\
\text { people }\end{array}$ & $\begin{array}{l}\text { Kinder- } \\
\text { garten }\end{array}$ & $\begin{array}{l}\text { Elementary } \\
\text { school }\end{array}$ & $\begin{array}{l}\text { Middle } \\
\text { school }\end{array}$ & High school & $\begin{array}{l}\text { Undergradu- } \\
\text { ate }\end{array}$ & Master & $\overline{\mathrm{PhD}}$ \\
\hline CMI in China & 55 & 55 & 54 & 47 & 25 & & \\
\hline EMI \& CMI & & & & 1 & 13 & & \\
\hline EMI oversea & & & 1 & 3 & 19 & 57 & 15 \\
\hline EMI in China & 2 & 2 & 2 & 6 & & & \\
\hline
\end{tabular}

Table 3.2. Note taking habits

\begin{tabular}{cccccc}
\hline & Always & Often & Sometimes & Seldom & Never \\
\hline Elementary & 5 & 15 & 23 & 13 & 1 \\
Middle & 13 & 20 & 16 & 4 & 4 \\
High & 25 & 21 & 9 & 1 & 1 \\
Undergrad & 14 & 25 & 11 & 6 & 1 \\
Master & 16 & 17 & 18 & 6 & 0 \\
PhD & 4 & 3 & 6 & 2 & 0 \\
\hline
\end{tabular}

Table 3.3. Language usage of note taking

\begin{tabular}{cccc}
\hline \multicolumn{4}{c}{ English Chinese translanguaging } \\
\hline Elementary school & 0 & 53 & 4 \\
Middle school & 0 & 36 & 21 \\
High school & 3 & 34 & 20 \\
Undergraduate & 18 & 12 & 27 \\
Master & 21 & 8 & 28 \\
PhD & 11 & 1 & 3 \\
\hline
\end{tabular}

\subsection{Allocation}

There are two different allocation approaches that were conducted for different analyses of this study. The first allocation approach was designed for the RQ1, which analyzed the relative effects of using different languages to take notes on lecture content understanding, knowledge retention, and note quality. In attempting to balance the three interventions with participants from different educational backgrounds, the following allocation approach was used. Participants were first stratified into three undergraduate language experience groups based on their responses provided in the background questionnaire. These three strata were "Undergrad in China only," "Undergrad in English only," and "Undergrad in both China and abroad." The top 33\% of each stratum was allocated to the "English intervention 
group." The middle $33 \%$ of each stratum was allocated to the "Chinese intervention group." The last 33\% of each stratum was allocated to the "translanguaging intervention group."

The second allocation approach was designed for RQ2, which analyzed the relative effects of previous study abroad experience on knowledge comprehension and retention test scores. Participants were allocated to three intervention groups based on their undergraduate experience: "Undergrad in China only," "Undergrad in English only," and "Undergrad in both China and abroad." See Table 4.1 and Figure 4.1 in Chapter 4 below for a full breakdown of the allocations used.

\subsection{Interventions}

Three interventions were compared. First, all participants completed the language background questionnaire. The survey link was distributed through the social media application WeChat, with each participant entering their assigned experimental ID number. Each group was instructed to take notes using Chinese, English, or translanguaging. In the note-taking phase, all participants watched a five-minute English-language video while taking notes simultaneously with pen and paper. They were only allowed to watch the video once and without any subtitles. Afterwards, in the review phase, they had four minutes to review the notes they took to prepare for the post-test. After this, a notification appeared to remind them to put away their notes and to not look at them during the comprehension test. They were allowed to finish the test at their own pace. In the feedback phase, participants could write down how they felt about the comprehension test to understand the participants' perception of the task. Lastly, all participants were required to send images of their notes to the researcher for the second phase of the study. After two weeks, the participants received a new link to the delayed retention test. Each participant had five minutes to review the images of their own notes from the initial note-taking phase. The notes disappeared after five minutes; then, participants could finish the retention test at their own pace.

\subsection{Materials}

\subsubsection{Test administration and data collection}

Qualtrics (Barnhoorn et al., 2015) was used for multiple aspects of this this study. It was used to make, distribute, and collect the participant information sheet (see Appendix B), the consent form (see Appendix C), the language background questionnaire (see Appendix D), and the comprehension/retention test (see Appendix E). Qualtrics is popular for researchers to use for non-interactive online experiments (Molnar, 2019). Specially, due to the COVID-19 pandemic, there were many restrictions on in-person meetings, making an online experiment software like Qualtrics perfect for this circumstance.

\subsubsection{Language background questionnaire}

All participants completed a Language Background Questionnaire before participating in the other two tests. The main goal of the questionnaire was to ensure eligibility for the study and to investigate participants' previous experiences with studying abroad during their undergraduate education. Those who took the questionnaire but were ineligible for the study were excluded before the allocation. The questionnaire was structured into eight sections. The first section covered basic information, containing questions on native language, second language, highest degree earned, current degree program and subject, and age at which they began learning English. The remaining sections focused on their previous language instruction experience, covering kindergarten, elementary school, middle school, high school, undergraduate program, master's program, and/or Ph.D. program.

\subsubsection{Video lecture}

The video used in this experiment is from the TED-Ed (2021) YouTube channel. The length of the video is 5:03 minutes with 2.16 words per second and embedded in the experiment through Qualtrics (see Appendix F). The video features a presentation about the history of concrete, the way modern concrete has contributed to carbon dioxide emissions, and solutions to solve these problems. This content was chosen because the speech rate is similar to lecture speech, allowing participants to take notes. Also, the vocabulary in the video was not overly academic, which made it fair for participants with different academic backgrounds. The topic discussed was not entirely unfamiliar to Chinese students, but the proposed solutions for the issues were. The video was downloaded from YouTube and embedded before the comprehension test to make sure all participants watched the video without subtitles in any language. All participants were told they could watch the video only once.

\subsubsection{Comprehension and retention tests}

The comprehension and retention tests in this study were identical and were partially adapted from Park's (2019) study, which used different types of questions to measure participants' comprehension and retention ability of various aspects of the lecture. Both tests used the same 22 questions in the same order, which were designed to cover all the information presented in the video. The questions were broken into three types: seven numerical questions, nine factual questions, and six main topic questions. Numerical questions asked specifically about numbers mentioned in the video, such as asking how many ingredients there are in cement and what percentage of emissions are produced by refrigerating. See Appendix E below for the full list of test questions. 


\subsection{Analysis strategy}

\subsubsection{Comprehension and retention test scoring}

Both comprehension and retention tests used the same questions. All three types of questions were scored by the researcher in the same way, based on how much correct information each question contained. For example, the question "what are the four ingredients of concrete?" was worth four points, because participants needed to answer with four ingredients, each being worth one point. If the participants did not answer the exact word from the video, but wrote a correct synonym, it was counted as correct as well, such as writing "greenhouse effect" instead of "global warming." For a full breakdown of the scoring used and acceptable answers (including main words, but not their synonyms), see Appendix E below. While this was the strategy for scoring, the participants were not aware of the amount of information required for full credit.

\subsubsection{Note Quality Standard}

There were two main criteria for evaluating participants' note quality: total word count and answerability. The standard for total English word count was adapted from Chaudron et al. (1988 as cited in Clerehan, 1995, p. 140; Chaudron, 1994; Dunkel, 1988); the definition of "word" in this study is "all orthographic units with spaces on each side" (except symbols and numbers). Numbers were not included as a part of the word count because it is hard to decide which language it belongs to when analyzing notes taken using translanguaging. For Mandarin note-taking, individual characters were counted as a word only if they were not a part of a compound, while compound words made of two or more characters were also counted as single words. For example, the compound “制造” (manufacturing) counted as one word because “制” and “造” as individual characters are not interpretable given the context. However, “加” (add) and “热” (hot) counted as two words because they have individual meanings in their contexts, and they are not a part of a compound in this case. Higher total word count was taken as an indication of lower cognitive load, showing how much information participants accessed by using the assigned note-taking language. The answerability criterion was adopted from Chaudron et al. (1994; Dunkel, 1988). It evaluates the number of word units that can be used to answer the questions on the comprehension and retention test, which indicates the usefulness of the notes. The third criterion is the proportion of each language used in translanguaging. The aim of this criterion is to find out which language was preferred when all linguistic resources were available to the note-takers.

\subsection{Ethical considerations}

The study was conducted in line with standard ethics guidance in the UK (BERA 2018) and approved by the University of Oxford's Central University Research Ethics Committee (CUREC) (see Appendix K).

\section{Results}

\subsection{Recruitment / Group Analysis}

All participants were recruited through social media and snowball sampling. Sixty-two participants completed the language background survey; however, five were not qualified as they were studying at Chinese universities, and another five were dropped due to lack of interest. Thus, 52 participants were recruited and randomly allocated to one of the three intervention groups. Following randomization, one participant was disqualified for not following instructions, having watched the video multiple times instead of just once. Another participant did only the comprehension test but was still included the analysis of the comprehension test results. This left 51 participants for the comprehension test analysis and 50 participants who did both the comprehension and retention tests. See Figure 4.1 below, where a CONSORT flow diagram shows the retention of participants through the trial. 


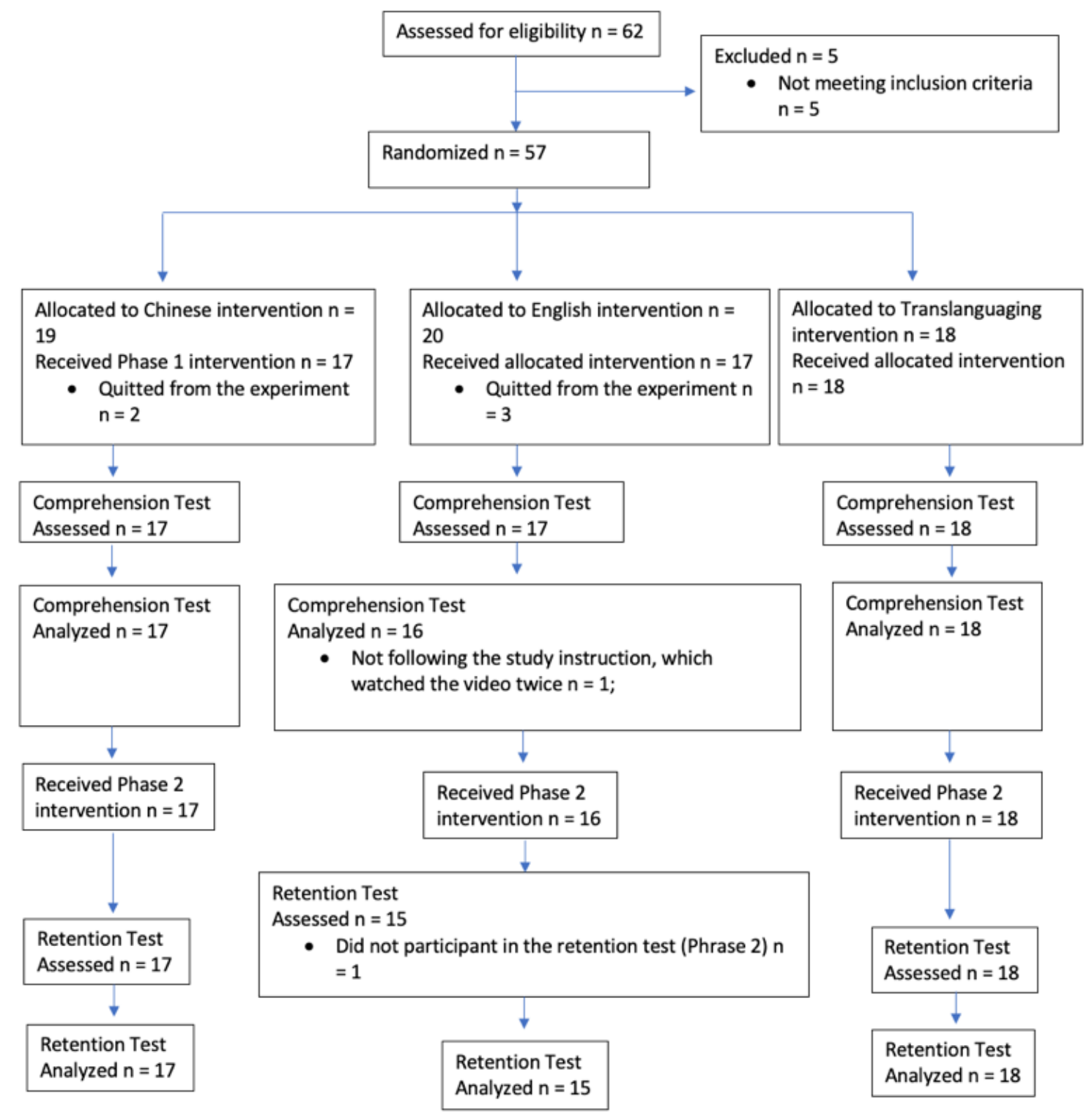

Figure 4.1. CONSORT Flow diagram

\subsection{Participants' information}

The questionnaire gathered participants' basic information and linguistic and education background. Participants consisted of 19 males and 32 females. Their age ranged from 21 to 39 years old, with an average of 23.9 years old. As for majors, 29 studied social sciences, 18 studied natural sciences, and four studied business. All participants said that their first language was Mandarin Chinese and had been learning English as a foreign language at least since elementary school around the age of six. There were 25 participants who completed their undergraduate degree in Chinese universities. These demographic results are presented below in Table 4.1. Three groups were originally evenly allocated based on undergrad study experience. However, due to some participants quitting the experiment after group allocation and material distribution, the final group allocation was not balanced.
Table 4.1. Participant's undergraduate education background information and their current majors

\begin{tabular}{cccc}
\hline $\begin{array}{c}\text { Instruction lan- } \\
\text { guage }\end{array}$ & Chinese only & English only & Translanguaging \\
\hline EMI & 4 & 7 & 6 \\
CMI & 10 & 8 & 7 \\
EMI \& CMI & 3 & 1 & 5 \\
Gender & $\mathrm{M}=7, \mathrm{~F}=10$ & $\mathrm{M}=5, \mathrm{~F}=11$ & $\mathrm{M}=7, \mathrm{~F}=11$ \\
& $\mathrm{M}=24.471, \mathrm{SD}=$ & $\mathrm{M}=23.533, \mathrm{SD}=$ & $\mathrm{M}=23.722, \mathrm{SD}=$ \\
Age & 4.064 & 1.407 & 2.469 \\
& Social Science $=9$ & Social Science $=10$ & Social Science $=10$ \\
Major & Science $=6$ & Science $=6$ & Science $=6$ \\
& Business $=2$ & Business $=0$ & Business $=2$ \\
\hline
\end{tabular}

\subsection{Comprehension test}

The first part of RQ1 concerned exploring the effects of taking notes using different languages on students' content comprehension. Total scores and the subset scores of different types of questions were analyzed separately to see if note-taking language had a different influence based on the types of information. Main topic questions focus on conceptual information, factual questions focus on detailed information, and numerical questions focus on numerical information. In this 
section, all data were analyzed via a one-way ANOVA, as the study compared scores across three different intervention groups. Before running the ANOVA, there were several issues that needed to be considered: significant outliers, normally distributed data, and homogeneity of variances (Field, 2013). Outliers were visualized with a boxplot, and measured with a sensitivity analysis (Figure 4.2, 4.3, $4.4 \& 4.5$ ). None of the outliers were found to affect the normal distribution of datasets regardless of question types. This was determined by skewness and kurtosis, as this experiment had a small sample (as recommended by Kim, 2013). (see Appendix J.1 \& J.2 for SPSS ANOVA results); thus, they are included in the analysis. According to Kim (2013), for sample sizes smaller than 50 participants, skewness and kurtosis values are between \pm 1.96 can represent normal distribution. Additionally, Levene's test was used to test the assumption of homogeneity. When the assumption of homogeneity was met and the ANOVA result showed significant difference $(p<0.05)$, a post hoc Tukey test was used to determine where that significant difference was, following the recommendation of Field (2013). In the Tukey test, a p-value of $<$ 0.05 indicates that there is a significant difference between the two groups.

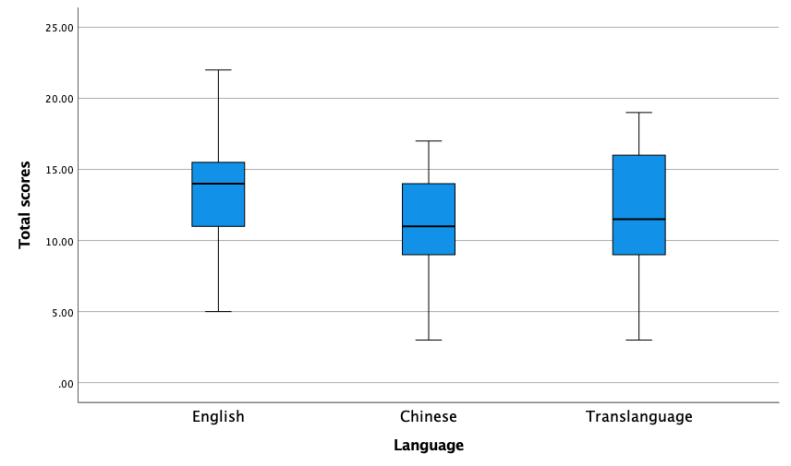

Figure 4.2. Points earned (out of 26) for all questions on the comprehension test by language

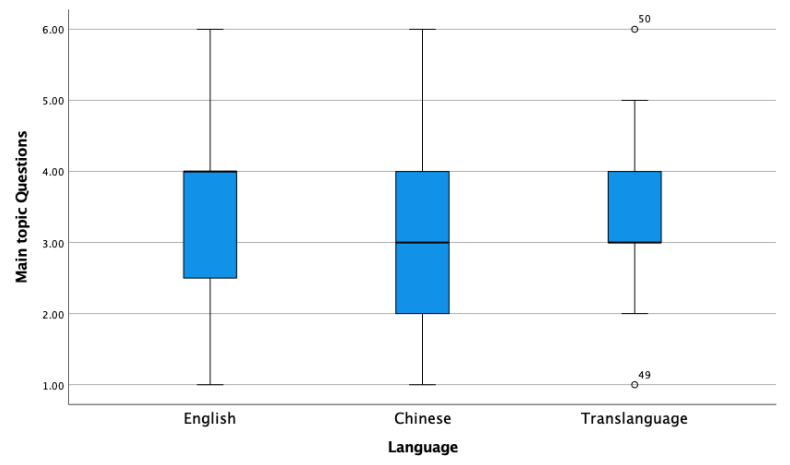

Figure 4.3. Points earned (out of seven) for main topic questions on the comprehension test by language

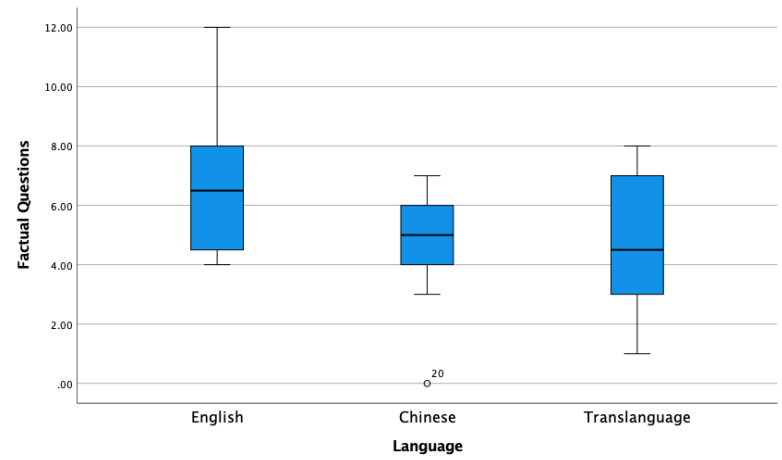

Figure 4.4. Points earned (out of 12) for factual questions on the comprehension test by language

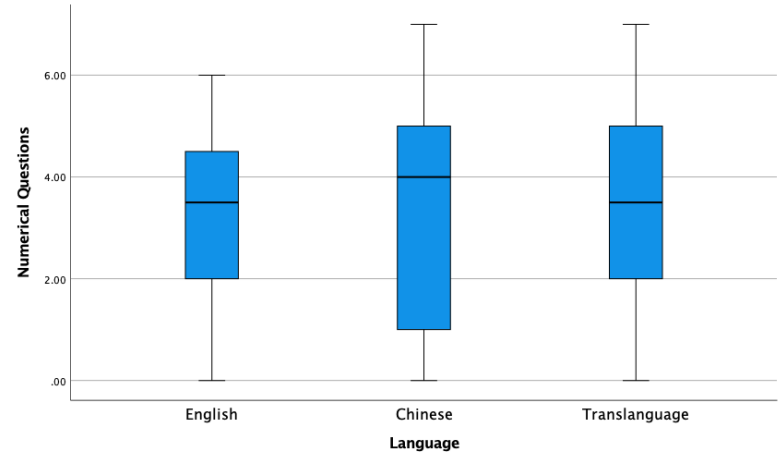

Figure 4.5. Points earned (out of seven) for numerical questions on the comprehension test by language

\subsubsection{Total scores}

The boxplot (Figure 4.2) above showed no significant outliers for any of the three intervention groups. The results of both skewness and kurtosis values were within the range of \pm 1.96 , meaning the data were normally distributed (Table 4.2) (Kim, 2013). Also, the result of homogeneity of variances was $p=0.88$, which means variance was not significantly different among the groups. An ANOVA was conducted, showing no significant difference among the interventions $(p=$ 0.34). The total scores on the comprehension test were English Only Group $(M=13.31, S D=4.36)$, Translanguaging Group $(M=11.89, S D=4.43)$, and Chinese Only Group $(M=11.18, S D=3.75)$ (Table 4.2). The one-way ANOVA revealed that there was no significant difference in scores between the three intervention groups $F(2,48)=1.10, p=0.34$ (Table 4.3). Therefore, we retain the null hypothesis, and reject the experimental hypothesis. In sum, using different languages to take notes did not influence the outcome of comprehension test overall outcome.

Table 4.2. Total scores of the comprehension test

\begin{tabular}{ccccc}
\hline Groups & $M$ & $S D$ & Skewness & Kurtosis \\
\hline English & 13.313 & 4.362 & -0.076 & 0.203 \\
Chinese & 11.177 & 3.746 & -0.464 & -0.118 \\
Translanguaging & 11.889 & 4.431 & -0.077 & -0.338 \\
\hline
\end{tabular}


Table 4.3. Results of one-way independent ANOVA of the total scores of comprehension test

\begin{tabular}{cccccc}
\hline & $S S$ & $d f$ & $M S$ & $F$ & $p$ \\
\hline Between & 38.824 & 2 & 19.412 & 1.104 & 0.340 \\
Groups & & & & & \\
Within & 843.686 & 48 & 17.577 & & \\
Groups & & & & & \\
Total & 882.510 & 50 & & & \\
\hline
\end{tabular}

\subsubsection{Scores of Main Topic Questions}

Another one-way ANOVA was used to measure whether participants using different languages to take notes performed differently on the main topic questions of the comprehension test. Two outliers assessed via visual inspection of boxplots, necessitating a sensitivity analysis, which concluded that the outliers did not affect the overall results (Appendix J.1). Also, homogeneity of variance was $p=0.83$, which means variance was not statistically significantly different. Since the ANOVA showed no significant differences among the groups, there was no need to run additional Tukey test. The main topic questions' scores of English Only Group $(M=3.56, S D=1.41)$, Translanguaging Group $(M=3.44, S D=1.25)$, and Chinese Only Group $(M=$ $3.18, S D=1.38)$, but there was not significant difference between these language groups $F(2,48)=0.360$, $p=0.699$ (Table $4.4 \& 4.5$ ). Therefore, we retain the null hypothesis, and reject the experimental hypothesis. In short, using different languages to take note did not influence participants understanding of the main topics.

Table 4.4. Main topic questions' scores of the comprehension test

\begin{tabular}{ccccc}
\hline Groups & $M$ & $S D$ & Skewness & Kurtosis \\
\hline English & 3.563 & 1.413 & 0.098 & -0.297 \\
Chinese & 3.177 & 1.380 & 0.129 & -0.395 \\
Translanguaging & 3.444 & 1.247 & 0.244 & 0.033 \\
\hline
\end{tabular}

Table 4.5. Results of one-way independent ANOVA of the main topic questions' scores of the comprehension test

\begin{tabular}{cccccc}
\hline & $S S$ & $d f$ & $M S$ & $F$ & $p$ \\
\hline $\begin{array}{c}\text { Between } \\
\text { Groups }\end{array}$ & 1.304 & 2 & 0.652 & 0.360 & 0.699 \\
$\begin{array}{c}\text { Within } \\
\text { Groups }\end{array}$ & 86.853 & 48 & 1.809 & & \\
Total & 88.157 & 50 & & & \\
\hline
\end{tabular}

\subsubsection{Scores of factual questions}

Another one-way ANOVA was used to determine whether participants using different languages to take notes had various outcome on factual questions in the comprehension test. Based on visual inspection of the boxplots, there was one outlier, necessitating a sensitivity analysis, which showed that the outliers did not affect the overall results (Appendix J.2). Therefore, the outlier was kept in the data. Homogeneity of variance was confirmed by Levene's test $(p=0.41)$. Scores were English Only Group $(M=6.56, S D=2.28)$, Translanguaging Group $(M=4.94, S D=2.13)$, and
Chinese Only Group ( $M=4.77, S D=1.82)$, and there was a significant difference between these language groups $F(2,48)=3.72, p=0.032, \eta^{2}=0.13$ (Table 4.6 $\& 4.7)$. In a post hoc analysis, a Tukey test showed a difference in factual questions' score only between the English and Chinese Only Groups (1.80, 95\% CI [0.04, $3.55], p=0.043)$. Therefore, we retain the experimental hypothesis and reject the null hypothesis. Overall, taking notes in English appeared to be more effective than taking notes in Chinese for comprehension of specific facts from the video lecture.

Table 4.6. Factual questions' scores of the comprehension test

\begin{tabular}{ccccc}
\hline Groups & $M$ & $S D$ & Skewness & Kurtosis \\
\hline English & 6.563 & 2.279 & 0.776 & 0.491 \\
Chinese & 4.765 & 1.821 & -1.013 & 1.536 \\
Translanguaging & 4.944 & 2.127 & -0.125 & -1.110 \\
\hline
\end{tabular}

Table 4.7. Results of one-way independent ANOVA of the factual questions' scores of the comprehension test

\begin{tabular}{ccccccc}
\hline & $S S$ & $d f$ & $M S$ & $F$ & $p$ & $\eta^{2}$ \\
\hline Between & 32.216 & 2 & 16.108 & 3.718 & 0.032 & 0.134 \\
Groups & & & & & & \\
Within & 207.941 & 48 & 4.332 & & & \\
Groups & & & & & & \\
Total & 240.157 & 50 & & & & \\
\hline
\end{tabular}

\subsubsection{Scores of numerical questions}

The numerical questions' scores were analyzed through a one-way ANOVA. The numerical questions focus information related to numbers in the video lecture. Based on a visual inspection of the boxplot, there were no outliers. The data were normally distributed based on a calculation of skewness and kurtosis (Table 4.8), Also, homogeneity of variances was determined using Levene's test, which found that the variance was equal $(p=0.75)$. The numerical questions' scores were English Only Group $(M=3.19, S D=1.97)$, Translanguaging Group $(M=3.5, S D=2.15)$, and Chinese Only Group $(M=3.24, S D=2.22)$, but there was no significant difference among these language groups $F(2,48)=0.109, p=0.90$ (Table $4.8 \& 4.9$ ). As a result, we retain the null hypothesis, and reject the experimental hypothesis. In short, using different languages to take notes did not affect participants understanding of the numerical information.

Table 4.8. Numerical questions' scores of the comprehension test

\begin{tabular}{ccccc}
\hline Groups & $M$ & $S D$ & Skewness & Kurtosis \\
\hline English & 3.188 & 1.973 & -0.416 & -0.675 \\
Chinese & 3.235 & 2.223 & -0.181 & -1.120 \\
Translanguaging & 3.500 & 2.149 & 0.060 & -0.711 \\
\hline
\end{tabular}


Table 4.9. Results of one-way independent ANOVA of the numerical questions' scores of the comprehension test

\begin{tabular}{cccccc}
\hline & $S S$ & $d f$ & $M S$ & $F$ & $p$ \\
\hline Between Groups & 0.984 & 2 & 0.492 & 0.109 & 0.897 \\
Within Groups & 215.996 & 48 & 4.500 & & \\
Total & 216.980 & 50 & & & \\
\hline
\end{tabular}

\subsection{Retention test}

The tools that used to analyze outliers and normality are as same as 4.3 section. The results of outliers accessed by boxplot were listed below (Figure 4.10, $4.11,4.12 \& 4.13)$. The four outliers in the total scores' dataset did not affect the overall results, as assessed by a sensitivity analysis (see Appendix J.3). However, both standard ANOVAs and modified Welch ANOVAs were used for analyzing different types of questions due to the assumption of homogeneity of variance not being met in some cases. In addition to the Tukey test, the Games-Howell test was also used in this section. The Games-Howell test was used for comparing scores between groups when homogeneity of variances was not met (Field, 2013). As mentioned earlier, the retention test results include 17 participants for the Chinese group, 15 participants for the English group, and 18 participants for the Translanguaging group, differing from the comprehension group.

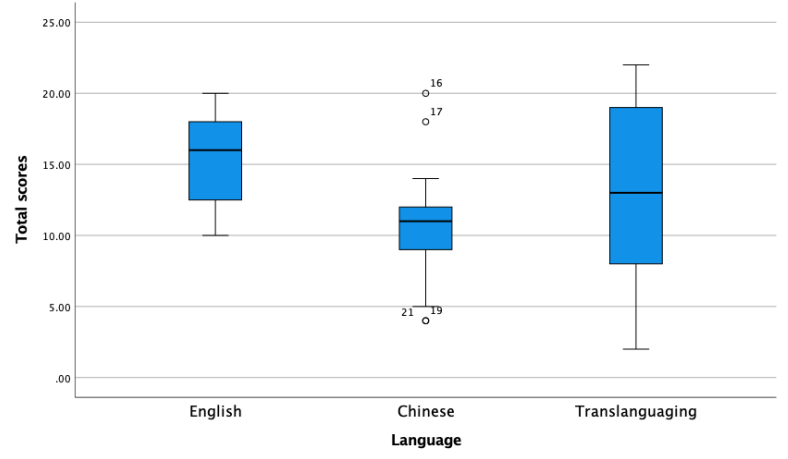

Figure 4.10. Points earned (out of 26) for all questions on the retention test by language

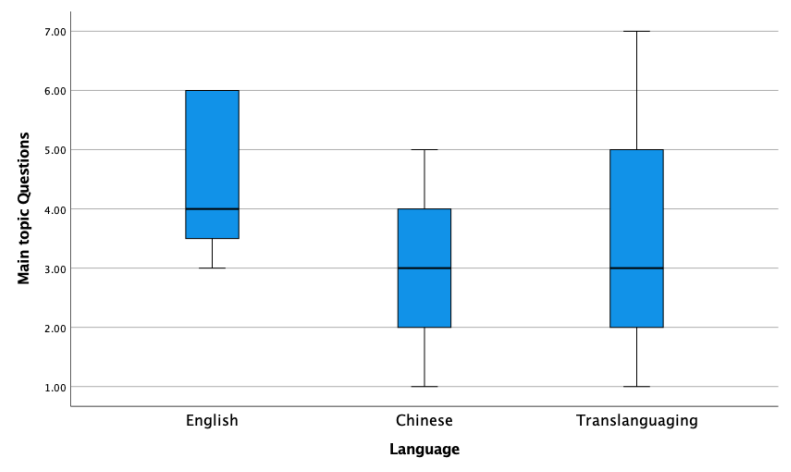

Figure 4.11. Points earned (out of seven) for main topic questions on the retention test by language

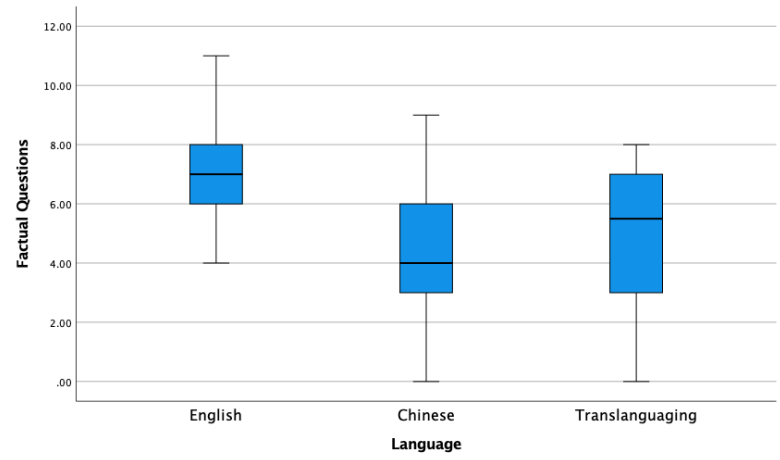

Figure 4.12. Points earned (out of 12) for factual questions on the retention test by language

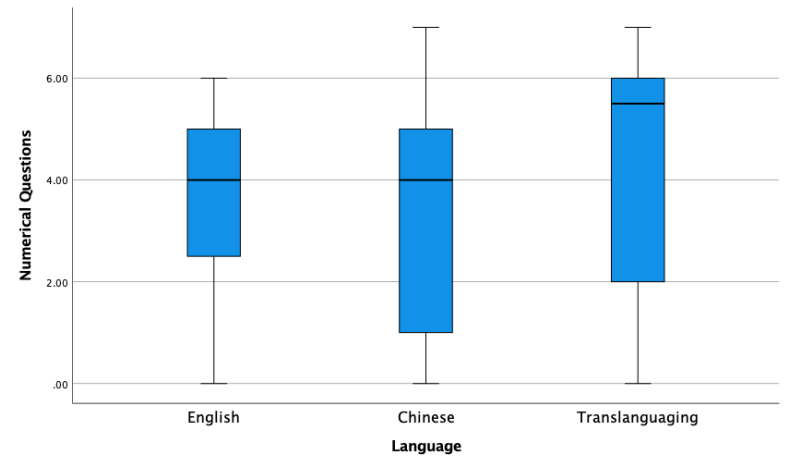

Figure 4.13. Points earned (out of seven) for numerical questions on the retention test by language

\subsubsection{Total scores}

A one-way Welch ANOVA was run to see whether participants using different languages to take notes differ in how well they do on the retention test's overall scores. The reason for using this kind of ANOVA is due to the heterogeneity of variances in the data (Levene's test shows $p<0.05(p=0.028))$. When homogeneity of variance was violated, a modified version of ANOVA (Welch) should be used (Field, 2013). The values of skewness and kurtosis were within the range of \pm 1.96 , which means the data were normally distributed (Table 4.10). The total score of the retention test were: English Only Group $(M=15.067, S D=3.634)$, Translanguaging Group $(M=12.889, S D=6.018)$, and Chinese Only Group $(M=10.824, S D=4.217)$. Since the result of Welch test was significant $F(2,31.091)=4.586, p$ $=0.018, \eta^{2}=0.12$ (Table 4.11), a Games-Howell test was used to examine the difference between groups. It showed that only the differences in total score between the Chinese Only Group and the English Only Group (4.234, 95\% CI [0.821, 7.664], $p=0.013)$ were statistically significant. Therefore, we retain the experimental hypothesis, and reject the null hypothesis. In summary, taking notes in English appeared to be more effective than taking notes in Chinese for overall retention of the lecture information. 
Table 4.10. Total scores of the retention test

\begin{tabular}{ccccc}
\hline Groups & $M$ & $S D$ & Skewness & Kurtosis \\
\hline English & 15.067 & 3.634 & -0.206 & -1.610 \\
Chinese & 10.824 & 4.217 & 0.315 & 0.768 \\
Translanguaging & 12.889 & 6.018 & -0.204 & -1.209 \\
\hline
\end{tabular}

Table 4.11. Results of Welch ANOVA of the total scores of the retention test

\begin{tabular}{ccccc}
\hline & Statistic & $d f 1$ & $d f 2$ & $p$ \\
\hline Welch & 4.586 & 2 & 31.091 & 0.018 \\
\hline
\end{tabular}

\subsubsection{Scores of main topic questions}

A one-way Welch ANOVA was implemented to investigate whether participants using different languages to take notes have various performance on main topic questions. Again, there was a heterogeneity of variance as shown by Levene's test $(p<0.05)$, which required the use of the Welch ANOVA. The skewness and kurtosis values, which were in between \pm 1.96 , indicating the data were normally distributed (Table 4.12). Also, based on the boxplot there were no outliers. The scores for main topic questions were: English Only $(M$ $=4.467, S D=1.246)$, Translanguaging Group $(M=$ 3.722, $S D=1.903)$, and Chinese Only Group $(M=3$, $S D=1.118)$. Because of the result of Welch ANOVA was significant $F(2,30.431)=5.971, p=0.006, \eta^{2}=$ 0.14 (Table 4.13), a Games-Howell test was used to examine the difference between groups. It showed that only the main topic questions' scores of the Chinese Only and English Only Groups (1.467, 95\% CI [0.426, $2.507], p=0.004)$ was significantly different. As a result, we retain the experimental hypothesis, and reject the null hypothesis.

Table 4.12. Main topic questions' scores of the retention test

\begin{tabular}{ccccc}
\hline Groups & $M$ & $S D$ & Skewness & Kurtosis \\
\hline English & 4.467 & 1.246 & 0.215 & -1.650 \\
Chinese & 3.000 & 1.118 & -0.304 & -0.393 \\
Translanguaging & 3.722 & 1.903 & 0.160 & -1.360 \\
\hline
\end{tabular}

Table 4.13. Results of Welch ANOVA of the main topic questions' score of the retention test

\begin{tabular}{ccccc}
\hline & Statistic & $d f 1$ & $d f 2$ & $p$ \\
\hline Welch & 5.971 & 2 & 30.431 & 0.006 \\
\hline
\end{tabular}

\subsubsection{Scores of factual questions}

To determine whether participants using different languages to take notes have various scores on factual questions in the retention test, a one-way ANOVA was conducted. The data was normally distributed based on the values of skewness and kurtosis (Table 4.14). In addition, homogeneity of variances existed which determined by Levene's test $(p=0.255)$. The scores were: English Only Group $(M=6.933, S D=1.751)$, Translanguaging Group $(M=5, S D=2.521)$, and Chinese Only Group $(M=4.588, S D=2.373)$, with a significant difference between these language groups $F(2$, $47)=4.803, p=0.013, \eta^{2}=0.17$ (Table $4.14 \& 4.15$ ). A post hoc Tukey test was conducted and showed the scores of the Chinese Only Group and English Only
Group $(2.345,95 \%$ CI $[0.404,4.287])$ on factual questions were significantly different $(p=0.014)$ as well as the scores of Translanguaging Group and English Only Group $(1.933,95 \%$ CI $[0.0172,3.849] ; p=0.048)$. No significant difference between Chinese Only and Translanguaging Groups was found. As a result, we retain the experimental hypothesis, and reject the null hypothesis. In sum, taking notes in English was more effective than taking notes in either Chinese or using a translanguaging approach for retention of factual information.

Table 4.14. Factual questions' scores of the retention test

\begin{tabular}{ccccc}
\hline Groups & $M$ & $S D$ & Skewness & Kurtosis \\
\hline English & 6.933 & 1.751 & 0.577 & 0.903 \\
Chinese & 4.588 & 2.373 & 0.082 & -0.378 \\
Translanguaging & 5.000 & 2.521 & -0.670 & -0.572 \\
\hline
\end{tabular}

Table 4.15. Results of one-way independent ANOVA of the factual questions' scores of the retention test

\begin{tabular}{cccccc}
\hline & $S S$ & $d f$ & $M S$ & $F$ & $p$ \\
\hline Between Groups & 49.269 & 2 & 24.635 & 4.803 & 0.013 \\
Within Groups & 241.051 & 47 & 5.129 & & \\
Total & 290.320 & 49 & & & \\
\hline
\end{tabular}

\subsubsection{Scores of Numerical Questions}

A one-way ANOVA was used to examine whether participants using different languages to take notes had different performance on numerical questions in the retention test. Based on the boxplot, there were no outliers. According to the results of skewness and kurtosis, the data was normally distributed (Table 4.16), and homogeneity of variances $(p=0.425)$ was confirmed by Levene's test. The scores of numerical questions in the retention test were: English Only Group $(M=3.667, S D$ $=2.093)$, Translanguaging Group $(M=4.111, S D=$ $2.494)$, and Chinese Only Group $(M=3.235, S D=$ 2.278 ), but there was no significant difference between these language groups $F(2,47)=0.630, p=0.537$ (Table $4.16 \& 4.17)$. Therefore, we retain the null hypothesis, and reject the experimental hypothesis. In short, using different languages to take note did not influence participants' retention of numerical information.

Table 4.16. Numerical questions' scores of the retention test

\begin{tabular}{ccccc}
\hline Groups & $M$ & $S D$ & Skewness & Kurtosis \\
\hline English & 3.667 & 2.093 & -0.675 & -0.782 \\
Chinese & 3.235 & 2.278 & 0.103 & -1.331 \\
Translanguaging & 4.111 & 2.494 & -0.526 & -1.385 \\
\hline
\end{tabular}

Table 4.17. Results of one-way independent ANOVA of the numerical questions' scores of the retention test

\begin{tabular}{cccccc}
\hline & $S S$ & $d f$ & $M S$ & $F$ & $p$ \\
\hline Between Groups & 6.710 & 2 & 3.355 & 0.630 & 0.537 \\
Within Groups & 250.170 & 47 & 5.323 & & \\
Total & 256.880 & 49 & & & \\
\hline
\end{tabular}




\subsection{Note Quality}

ANOVAs were used to analyze the data as it can compare two groups. If the result of an ANOVA was significant $(p<0.05)$, then a Tukey test was used for further analysis between groups. Also, Levene's test was used to test the assumption of homogeneity. In addition, skewness and kurtosis were used to examine normality, as the sample size was small $(\mathrm{n}=50)(\mathrm{Kim}$, 2013). The data were considered normally distributed if their skewness and kurtosis values are between \pm 1.96 . Beyond this, one outlier was visible in a boxplot for total word count (Figure $4.14 \& 4.15$ ); however, a sensitivity test showed this outlier did not affect the overall outcome or distribution of the data (Appendix J.4). Thus, the outlier was included in the dataset and will not be further discussed in this section. See Appendix I for the datasets.

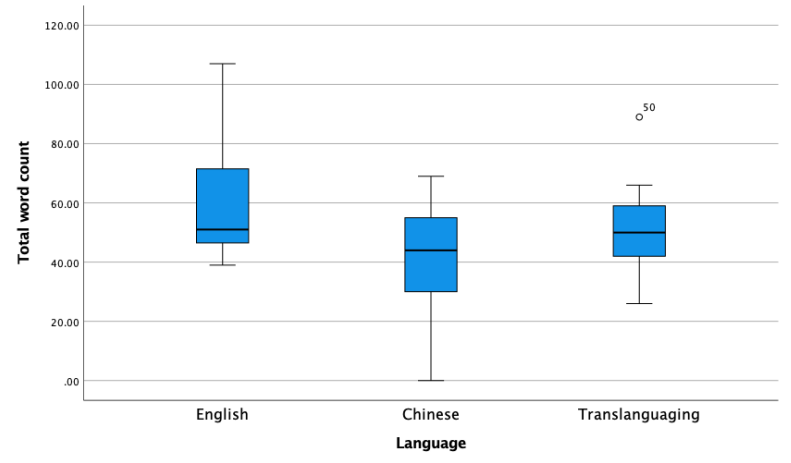

Figure 4.14. Total word count of notes by language

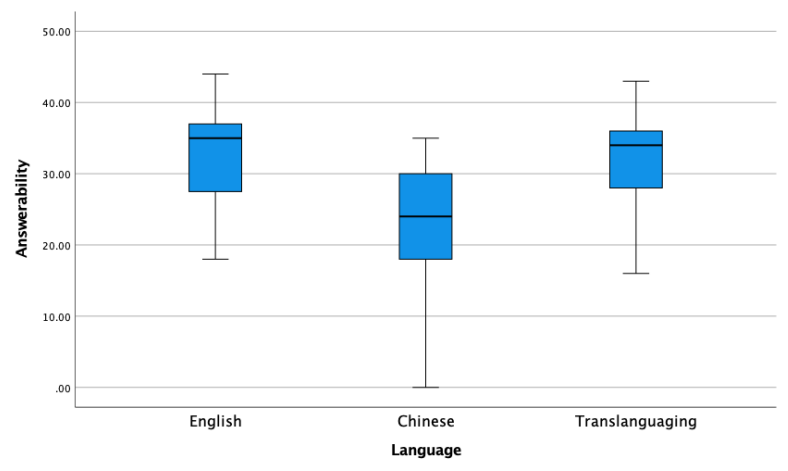

Figure 4.15. Scores of answerability of notes by language

\subsubsection{Total word count}

A one-way ANOVA was used to determine whether participants using different languages to take notes had differences in the word count of their notes. All vocabulary and abbreviations that appears in the notes count towards the total word count for note-taking in English. Individual characters were counted as a word only if they were not a part of a compound, while compound words made of two or more characters were also counted as single words for note-taking in Chinese. Due to the small sample size, skewness and kurtosis values were used to assess normality, which showed the data is normally distributed (Table 4.18). Also, the result of homogeneity of variances was $p=0.308$, which means results of a standard ANOVA can be used. The total word counts were: English Only Group ( $M=$ $59.733, S D=20.974)$, Translanguaging Group $(M=$ $50.889, S D=15.025)$, and Chinese Only Group $(M=$ $41.235, S D=17.466$ ) (Table 4.18). There was significant difference between these language groups $F(2,47)$ $=4.325, p<0.05, \eta^{2}=0.155$ (Table 4.19), and in a post hoc analysis, a Tukey test was conducted to show that only the difference in total word count of the Chinese Only Group and English Only Group (18.498, 95\% CI $[3.245,33.7513])$ were statistically significant $(p=$ 0.014 ). As a result, we retain the experimental hypothesis, and reject the null hypothesis. In sum, the participants wrote more words while taking notes in English than those doing so in Chinese.

Table 4.18. Total word count of each participants' notes

\begin{tabular}{ccccc}
\hline Groups & $M$ & $S D$ & Skewness & Kurtosis \\
\hline English & 59.733 & 20.974 & 1.273 & 0.785 \\
Chinese & 41.235 & 17.466 & -0.573 & 0.460 \\
Translanguaging & 50.889 & 15.025 & 0.627 & 1.225 \\
\hline
\end{tabular}

Table 4.19. Results of one-way independent ANOVA of the total word count of each participants' notes

\begin{tabular}{cccccc}
\hline & $S S$ & $d f$ & $M S$ & $F$ & $p$ \\
\hline Between Groups & 2737.850 & 2 & 1368.925 & 4.325 & 0.019 \\
Within Groups & 14877.770 & 47 & 316.548 & & \\
Total & 17615.620 & 49 & & & \\
\hline
\end{tabular}

\subsubsection{Scores of answerability}

A one-way ANOVA was used to compare the answerability of the notes taken by participants using different languages. Answerability is the number of words that can be used as answers to the questions on the comprehension/retention tests and was taken as a measurement of the effectiveness of the notes. The data was normally distributed based on skewness and kurtosis (Table 4.20), and homogeneity of variances existed which determined by Levene's test $(p=0.969)$. The results of answerability were: English Only Group $(M=$ $32.467, S D=7.726)$, Translanguaging Group $(M=$ $31.222, S D=8.179)$, and Chinese Group $(M=23.765$, $S D=9.169$ ) (Table 4.20). There was significant difference between these language groups $F(2,47)=5.205$, $p<0.05, \eta^{2}=0.181$ (Table 4.21). In a post hoc analysis, a Tukey test was conducted to show that the difference in answerability of the Chinese Only Group and English Only Group (8.702, 95\% CI [1.500, 15.905]) was statistically significant ( $p=0.014)$, as well as the answerability scores of the Chinese Only and Translanguaging Groups $(7.458,95 \%$ CI $[0.581$, $14.334] ; p=0.031)$. As a result, we retain the experimental hypothesis, and reject the null hypothesis. In sum, taking notes in English and translanguaging led to higher answerability scores than taking notes in Chinese while watching the video lecture. 
Table 4.20. Answerability of each participants' notes

\begin{tabular}{ccccc}
\hline Groups & $M$ & $S D$ & Skewness & Kurtosis \\
\hline English & 32.467 & 7.726 & -0.444 & -0.606 \\
Chinese & 23.765 & 9.169 & -1.088 & 1.333 \\
Translanguaging & 31.222 & 8.179 & -0.652 & -0.460 \\
\hline
\end{tabular}

Table 4.21. Results of one-way independent ANOVA of the answerability of each participants' notes

\begin{tabular}{cccccc}
\hline & $S S$ & $d f$ & $M S$ & $F$ & $p$ \\
\hline Between Groups & 734.917 & 2 & 367.458 & 5.205 & 0.009 \\
Within Groups & 3317.903 & 47 & 70.594 & & \\
Total & 4052.820 & 49 & & & \\
\hline
\end{tabular}

4.6. Undergraduate experience on the comprehension and the retention tests

The second research question sought to investigate whether undergraduate study abroad experience affects students' performance on comprehension and retention test scores. This section first analyzes the comprehension test results in light of undergraduate study abroad experience, followed by the same for the results of the retention test. Participants were categorized into three groups, based on their answers to the background questionnaire: Abroad group $(\mathrm{n}=17)$, China group $(\mathrm{n}=25)$, and Abroad + China group $(\mathrm{n}=$ 9) for the comprehension test, with one participant dropping out of the China group before the retention test. Outliers were assessed by boxplot (Figure 4.16 \& 4.17). There was one outlier in each of the datasets. Moreover, the outliers affected the normally distributed of the datasets; as a result these outliers were excluded and will not be discussed further. In this section, all data were analyzed via a one-way ANOVA, and the Tukey test was used for further analysis between groups when necessary. Additionally, Levene's test was used to test the assumption of homogeneity.

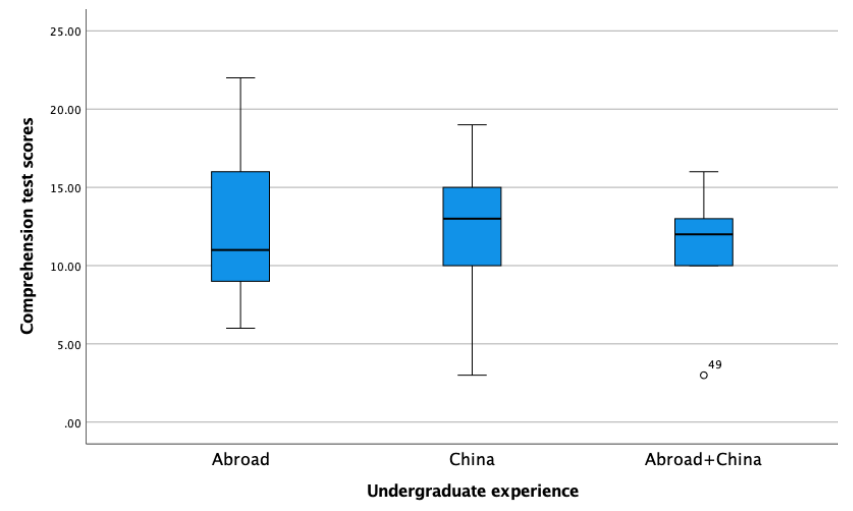

Figure 4.16. Points earned (out of 26) for all questions on the comprehension test by education experience

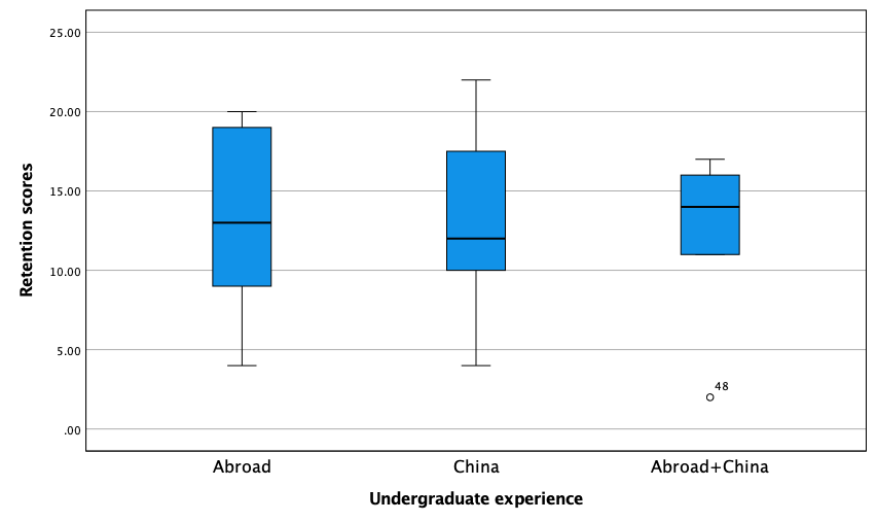

Figure 4.17. Points earned (out of 26) for all questions on the retention test by education experience

\subsubsection{Comprehension test scores}

A one-way ANOVA was used to measure whether participants' previous undergraduate study abroad experience played a role in their comprehension test scores. Homogeneity of variances $(p=0.091)$ was determined by Levene's test, showing variance was equal. The results for the comprehension test were: Abroad + China $(M=12.625, S D=2.134)$, Abroad $(M=12.412$, $S D=4.317)$, China Group $(M=12.080, S D=4.406)$, but there was not significant difference between these language groups $F(2,47)=0.066, p=0.936$ (Table $4.22 \& 4.23)$. As a result, we retain the null hypothesis, and reject the experimental hypothesis. In sum, previous undergraduate study experience did not influence participants' comprehension ability of the video lecture.

Table 4.22. Comprehension test results of previous study experience

\begin{tabular}{ccccc}
\hline Groups & $M$ & $S D$ & Skewness & Kurtosis \\
\hline Abroad & 12.412 & 4.317 & 0.680 & -0.211 \\
China & 12.080 & 4.406 & -0.341 & -0.552 \\
Abroad + & 12.625 & 2.134 & 0.300 & -0.653 \\
China & & & & \\
\hline
\end{tabular}

Table 4.23. Results of one-way independent ANOVA of comprehension test results of previous study experience

\begin{tabular}{cccccc}
\hline & $S S$ & $d f$ & $M S$ & $F$ & $p$ \\
\hline Between Groups & 2.247 & 2 & 1.124 & 0.066 & 0.936 \\
Within Groups & 795.833 & 47 & 16.933 & & \\
Total & 798.080 & 49 & & & \\
\hline
\end{tabular}

\subsubsection{Retention test scores}

A one-way Welch ANOVA was implemented to investigate whether participants' previous undergraduate study abroad experience plays a role in their retention test scores. Levene's test showed a $p<0.05$ ( $\mathrm{p}=$ 0.040 ), indicating that homogeneity of variance was violated, which necessitated using a modified version of ANOVA (Welch) for analysis. The results of retention test scores were: China Group $(M=12.583, S D=4.763)$, Abroad Group $(M=13.118, S D=5.721)$, and Abroad + China Group $(M=14.375, S D=2.504)$, but there was 
no significant difference between groups, Welch $F$ (2, $25.971)=0.964, p>0.05$ (Table $4.24 \& 4.25$ ). As a result, we retain the null hypothesis, and reject the experimental hypothesis. In sum, previous undergraduate study experience did not influence participants' retention ability of the video lecture.

Table 4.24. Retention test results of previous study experience

\begin{tabular}{ccccc}
\hline Groups & $M$ & $S D$ & Skewness & Kurtosis \\
\hline Abroad & 13.118 & 5.721 & -0.130 & -1.546 \\
China & 12.583 & 4.763 & 0.246 & -0.513 \\
Abroad + China & 14.375 & 2.504 & -0.422 & -1.654 \\
\hline
\end{tabular}

Table 4.25. Results of Welch ANOVA of retention test results of previous study experience

\begin{tabular}{ccccc}
\hline & Statistic & $d f 1$ & $d f 2$ & $p$ \\
\hline Welch & 0.946 & 2 & 25.971 & 0.401 \\
\hline
\end{tabular}

\section{Discussion}

\subsection{Note quality}

\subsubsection{Total word count}

The total word count showed that on average, participants wrote more words down while using English $(\mathrm{M}=59.733)$ rather than Chinese $(\mathrm{M}=41.235)$. This implies that participants taking notes in English were more comprehensive than those taking notes using Chinese. One possible reason for this result is that the participants were simply more comfortable and have high proficiency in their L2. In the literature review, Swain \& Lapkin (2000) and Scott \& Fuente (2008) claimed that the additional cognitive load required in L2 was due to deficiency in L2, and using L1 could free up some cognitive loads. However, if participants are equally or more proficient in L2 than L1, then using L1 might not reduce some cognitive loads on note-taking, as seen in this study. It is reasonable to assume that the participants here may not have proficiency issues in their L2. First, all participants were currently studying in a grad program that was taught in English, which can generally be taken to mean that participants have enough English proficiency to understand a fairly high level of lecture content. Second, half of the participants had experience in EMI before their graduate programs, and 17 of them even received their bachelor's degrees in an English-speaking country. Thus, all participants were used to listening to and communicating in English. Furthermore, with many of them staying in an Englishspeaking country (due to the Covid-19 some of the participants were not able to travel abroad to their programs), they could have been using more English than Chinese during the time prior to the study, making them in better practice with their L2 than their L1. Third, the difficulty of the lecture in this study was probably less than what the participants encounter in their programs, so it is reasonable to assume that participants may not have had language difficulties in this case, even if they were unfamiliar with the topic. Taken together, this means that while English is their L2, using it to take notes for a lecture in English might incur a lighter cognitive load than using their L1, because of their proficiency in English. It follows that if students are proficient in the target language and instructed to take notes in their L1, there might be negative effects on the quality of the notes (and thus later academic performance), because translating back to their L1, paraphrasing information, and writing the notes down would only increase the cognitive load necessary.

In sum, those using English could write down more words during note-taking because these high L2 proficiency students were perfectly comfortable taking notes in L2, indicating that using L2 uses less cognitive load and/or less time for at least high proficiency L2 students. Moreover, switching back to Chinese to record the information presented in might increase the cognitive load, and reduce the time available on notetaking. This study's finding contradicts with Park (2019) mostly likely due to the difference in participants' L2 proficiency among the studies. This study also confirms a prediction made in Faraco et al.'s (2000) study that processing L2 may not actually put more cognitive load on advanced L2 speakers.

\subsubsection{Answerability}

Answerability measured how many words in the notes could be used to answer questions on the retention test, which was taken as a measure of the usefulness of the notes. The results of comparing the answerability of the notes showed that participants who use English $(\mathrm{M}=32.467)$ or translanguaging $(\mathrm{M}=31.222)$ obtained a higher score than participants who used Chinese (23.765) to take notes. It is important to note that total word count does not always correlate with answerability, which was the case for some of the participants in this study. High total word count may have low answerability, and vice versa. The results of answerability showed that participants who use English to take notes did not simply write down all the words they heard; rather, they also processed the information and decided what information was worth writing down. Additionally, some information was written down using abbreviations to save time; this may have led to English taking less time to write than Chinese, so participants had the additional free time to notice and process key vocabulary and conceptual information. In addition, the reason that the translanguaging group $(\mathrm{M}=31.222)$ have performed better in answerability than the Chinese group $(M=23.765)$ was participants in the translanguaging group used more English $(\mathrm{M}=36.167$, $\mathrm{SD}=12.035)$ than Chinese $(\mathrm{M}=8.722, \mathrm{SD}=5.969)$ (see Appendix M), which indicates that given the choice, participants more often matched the language of the lecture, despite the fact it was their L2. This further supports that using English costs less cognitive load than other languages, allowing participants to capture, prioritize, and record the most important information.

\subsubsection{Participants' feedback}


All major relevant feedback has been summarized in this section (see Appendix L). Several participants in the Chinese Only Group reported that they felt it was quite hard to take notes in L1 for multiple reasons. First, they are used to taking notes in L2 when listening to L2 because they had already believed doing so would help them develop their L2 skills. Second, it was hard to translate back to L1, as they had barely any experience in listening to L2 while writing notes in L1, making it difficult for the students to translate and take notes at the same time. Furthermore, some participants reported that they used considerable time and effort in translating English into Chinese; regardless of experience with L2 lecture and L1 notes, this could have resulted in them having limited capacity to memorize or capture detailed information from the video lecture. In some specific cases, translation to Chinese was difficult because they could not recall the correct translation of some of the English vocabulary they encountered. Third, several participants reported they typed Chinese characters, using Pinyin (a Romanization system) as the keyboard input. Thus, even if they had the Chinese word in their mind, it may have taken more time to recall how to write it in characters. In some extreme cases, they simply wrote the Chinese words in Pinyin instead. Thus, the results here refute Swain and Lapkin's (2000) and Scott and Fuente's (2008) studies, that using L1 can lower students' cognitive load, because participants in this study had high L2 proficiency. Lastly, several participants who were in the Chinese Only Group reported that, in order to take the notes quickly enough to keep up with the English lecture speech rate, they often wrote a single character to represent a compound word. However, when they reviewed the notes before the retention test, they forgot which compound word that single character represented, as a single character in Chinese is often part of numerous compounds (Arcodia, 2007). One could speculate that this could be less of an issue in English, as English has many (semi-)standard abbreviations for different words, such as "bc" for "because" (De Jonge \& Kemp, 2012; Pratiwi \& Marlina, 2020).

The translanguaging group had different comments to offer. Some students reported that they preferred to take notes with this method because they had all their linguistic resources available to them. Based on their familiarity with different knowledge in different languages, they could write down information with the first language to come to mind, which was very convenient. Also, some students claimed that using translanguaging to take notes allowed them to use all their academic knowledge resources. They have certain academic knowledge learned in English, and some academic knowledge learned in Chinese, so using translanguaging to take notes made them feel as if they could link their knowledge directly without translating to another language. However, one student reported that he had some difficulties in taking notes in translanguaging. With both languages available, he felt he needed to first decide which language would be better to use for any given point. He mentioned that being limited to English would have been easier than having too many linguistic resources available for him to choose from.

\subsection{Comprehension test}

\subsubsection{Results}

The results showed there was no significant effect of using different note-taking languages on overall comprehension test scores. However, when the scores are broken down by question types, one significant difference does emerge. Fact-based questions were answered correctly more often by the group that used English $(\mathrm{M}=6.563)$ to take notes. The results indicate that note-taking language generally does not affect overall content comprehension level, but if anything, using the same language as the lecture can result in better comprehension of basic facts presented in a lecture.

\subsubsection{Explanation of the results}

One possible reason that note-taking language did not affect overall comprehension scores is from the combination of high L2 proficiency and short-term memory. Since all participants probably fully understood the lecture, and were doing the comprehension test based on their short-term memory rather than their notes, there was no difference between groups on overall comprehension test scores. However, there are multiple interpretations of the finding that fact-based questions in particular were more affected by note-taking language. First, these are the questions that require the most linguistic encoding. Factual questions focused on participants' comprehension of specific vocabulary and key information. Since all information for the Englishonly group was in English (lecture, notes, and test), the questions are more likely to have a more direct link to the knowledge encoded in English in participants' memory, resulting in priming, where an initial stimulus (here the English word) facilitates processing of the same stimulus in a second encounter (Segaert, 2019). Especially for factual questions, participants might have written the exact same word in their notes needed to answer the comprehension questions. However, if the notes were taken completely or partially in Chinese, then there would be an additional translation process needed when answering the questions of the comprehension test, which may not result in a consistent vocabulary item being used for the answer. This would put the English Only Group in a better position to do well on factual questions compared to either the Chinese Only or Translanguaging Groups (based on descriptive results).

In sum, the language in which notes were taken did not have an overall impact on the content comprehension level, but using English to take notes can enhance the linguistic encoding of detailed information.

\subsection{Retention test}

\subsubsection{Results}

The results of the retention test showed that taking notes in English (Overall $M=15.067$, Main Topic $M=$ 
4.467) is more effective than taking notes in Chinese (Overall $M=10.824$, Main Topic $M=3.0$ ) for both overall retention of lecture content and main topic questions. Additionally, the English Only Group $(M=$ 6.933) did better than either the Chinese Only $(M=$ $4.588)$ or Translanguaging Groups $(M=5.0)$ on factbased questions. However, note-taking language did not affect participants' retention of numerical information.

\subsubsection{Explanation of the results}

The lack of difference among the groups on numerical questions in the retention test can be explained in the same as it was in the comprehension test, where that majority of the participants write down numbers in Arabic numerals instead of either English or Chinese. Thus, note-taking language did not affect participants' understanding of numerical information from the video lecture. To explain the other results where English did better, three possible speculations can be made. First, as mentioned in the comprehension test section, both comprehension and retention tests were written in English, and the information was encoded in English. Thus, when the participants answer the questions in English, the questions would be more directly linked to the knowledge encoded in English in participants' memory, again priming them for the answer. Second, the total word count showed that participants in the English Only Group took the most notes, which means they have more information from their notes to review than other groups. Third, based on answerability, the English Only Group has more useful notes to review than other groups. Lastly, the reason taking notes in translanguaging did not lead to better performance on factual questions than the other group might be the use of Chinese, which required participants to switch languages, leading to more cognitive load.

Lastly, we must address why the results of the retention and comprehension were not the same - the difference in performance among the groups was larger in the retention test.

The first possible reason is related to note quality. Since the comprehension test was conducted right after the lecture, participants were able to use short-term memory to answer the questions. However, the retention test was conducted two weeks later. Ebbinghaus' forgetting curve (Chao et al., 2016) suggests that just after acquired the knowledge, $100 \%$ of the knowledge can be retained; but after 6-31 days of learning, only $21 \%-25 \%$ of the knowledge can be retained. Thus, it is reasonable to assume that a fair amount of information had been lost by all participants. Participants then had to rely on their notes to answer the test questions, so the note quality more directly affected participants' performance on the retention test. Based on the total word counts and answerability scores above, taking notes in English produced better notes to review before the retention test. The second possible reason is more straightforward in that reviewing notes in the same language as the test may be more helpful than looking at notes in other languages.
In sum, taking notes in the same language as the instruction language can assist participants to take better quality notes. Since the test and the notes are all in the same language, the questions are more directly linked to participants' information in their memory (Segaert, 2019).

\subsection{Implications}

\subsubsection{Implications for the literature}

Based on the results of my research, using translanguaging did not have much effect on content understanding or retention. In this case, using translanguaging to take notes is less effective than matching the language of the lecture. One may have expected that using translanguaging to take notes would be the most effective way, because all linguistic resources were available for the participants to use. However, as reported by one of the participants, it actually took some effort to decide which language to use while taking notes. In addition, the reason this study has different outcomes compared to the above studies is because the population of this study was highly proficient in their L2, the language of the lecture. Most translanguaging related studies have focused on participants who lack skills in either their L1 or L2 (Swain \& Lapkin, 2000; Scott \& Fuente, 2008; Cohen, 1994), using the high proficiency language to help develop the low proficiency language. However, this study's participants were fluent in both their L1 and L2, and so translanguaging offered no benefits. In addition, another difference between this study and previous ones is the purpose of using translanguaging. Studies described in my literature review focused more on classroom interaction and engagement, and showed translanguaging is helpful for these purposes. However, this study focuses on educational outcomes, and showed translanguaging to not be as beneficial as predicted, with results aligning with previous studies focused on educational outcomes.

\subsubsection{Pedagogical implications}

Confirmed advantages of using the translanguaging method in classes include social identity, understanding lecture content, and supporting linguistic minorities (Cenoz, 2017; Creese \& Blackledge, 2010). However, based on the current study, the benefits of translanguaging in note-taking are limited. Furthermore, other studies (Chalmers, 2019; Hopp et al., 2021) have also claimed that $\mathrm{L} 2$ acquisition is not affected by translanguaging. Therefore, schools and teachers should critically evaluate the effectiveness of using translanguaging if they have similar conditions as in this study.

In addition, instructions for note-taking should be different based on the purpose of the notes. If note-taking is being used for enhancing students' comprehension of the lecture content, then teachers should allow students to use the language they are most comfortable with to take notes to reduce the cognitive load required in note-taking. If notes are being used for improving 
students' retention skills or as a reviewing material, then the teacher should instruct students to take notes in the same language as instruction, since this strategy can more directly encode the information that will be needed for future use (whether in short-term memory, or the notes themselves). In sum, there is no best way to take notes for an entire class due to individual differences, and instructors should give students the flexibility to use the language they are most comfortable with to take notes. Although, if taking notes is for information retention purposes with high proficiency L2 speakers, then I would recommend using L2 to take notes.

\subsection{Limitations of the study}

One of the limitations of this study is related to the participant population. Participants were recruited through snowball sampling, which is not truly random, as some participants were acquaintances or classmates who might have similar English proficiency or notetaking habits. This reduction in the diversity of the sample is one of the characteristics of snowball recruiting. Second, the allocation of the participants was not fully random.

There are also a few aspects of the experimental design which limit the current study's generalizability. The questions on the comprehension and retention tests were in the same order as the content of the lecture video played. This may have caused some students to have answered the first few questions better because they had more energy to pay attention to the content introduced at the beginning of the lecture than a question whose information introduced at the end of the lecture. Future studies on translanguaging during note-taking could focus on different populations and languages, and other measures of educational outcomes.

\section{Conclusion}

Because participants were advanced learners of English, they were more comfortable in taking notes in English during an English lecture. Furthermore, matching the lecture language seems to promote better note quality than taking notes in one's native language or translanguaging. While note-taking language may not have a large impact on the overall content comprehension level, using English to take notes can enhance linguistic encoding of detailed content information. Overall, using the same language in note-taking and instruction can improve participants' retention of the content, at least when the students are proficient in the language. Additionally, participants' previous study experience does not impact content comprehension and retention ability. Importantly, this study showed that the translanguaging approach does not outperform the single language approach as far as educational outcomes are concerned, which is supporting the findings of other researchers (Chalmers, 2019; Hopp et al., 2021). Lastly, teachers should decide on the note-taking language to be used based on the purpose of the notes. This study suggests teachers should allow students to use the language they are most comfortable with for basic content comprehension purpose but suggests that teachers instruct students to use the same language as the instruction language to take notes for content retention purposes.

\section{Xinyi Wang}

Xinyi Wang obtained a bachelor's degree in applied linguistics from UCLA. Her research area at that time was focused on Shanghainese Tone Sandhi and English inflection recognition. Later, she continued her study at The University of Oxford, where she graduated with a master's degree in applied linguistics and second language acquisition from The Department of Education. Her research focus was on the effect of translanguaging on content comprehension and knowledge retention.

\section{References}

Arcodia, G. F. (2007). Chinese: A language of compound words. Selected proceedings of the 5 th décembrettes: Morphology in Toulouse, 79-90.

Barnhoorn, J. S., Haasnoot, E., Bocanegra, B. R., \& van Steenbergen, H. (2015). QRTEngine: An easy solution for running online reaction time experiments using Qualtrics. Behavior research methods, 47(4), 918-929.

https://doi.org/10.3758/s13428-014-0530-7

Brown, C. L. (2011). Maintaining heritage language: Perspectives of Korean parents. Multicultural Education, 19(1), 31-37.

Celic, C., \& Seltzer, K. (2011). Translanguaging: A CUNY-NYSIEB guide for educators. New York, NY: CUNY-NYSIEB.

Cenoz, J. (2017). Translanguaging in school contexts: International perspectives. Journal of Language, Identity \& Education, 16(4), 193-198. https://doi.org/10.1080/15348458.2017.1327816

Chalmers, H. W. (2019). Leveraging the L1: the role of EAL learners' first language in their acquisition of English vocabulary (Doctoral dissertation, Oxford Brookes University).

Chandler, P., \& Sweller, J. (1991). Cognitive load theory and the format of instruction. Cognition and instruction, 8(4), 293-332. https://doi.org/10.1207/s1532690xci0804_2

Chao, C. W., Chang, L., Cheng, A. C., \& Wu, T. T. (2016, October). Exploration on the effectiveness of learning, interest, and attitude of the integration of review system of history based on mobile game and forgetting curve. In International symposium on emerging technologies for education (pp. 34-42). Springer, Cham. https://doi.org/10.1007/978-3-319-52836-6_5

Chaudron, C., Cook, J., \& Loschky, L. (1988). Quality of lecture notes and second language listening comprehension (Tech. Rep. No. 7). Honolulu: University of Hawaii at Manoa. Center for Second Language Classroom Research.

Chaudron, C., Loschky, L., \& Cook, J. (1994). Second 
language listening comprehension and lecture note-taking. Academic listening: Research perspectives, 75-92.

https://doi.org/10.1017/cbo9781139524612.008

Clark, M., Wayland, S., Osthus, P., Brown, K. G., Castle, S., \& BA, A. R. (2013). The effects of note taking on foreign language listening comprehension. University of Maryland Center for Advanced Study of Language.

Clerehan, R. (1995). Taking it down: Note-taking practices of L1 and L2 students. English for specific purposes, 14(2), 137-155. https://doi.org/10.1016/0889-4906(95)00003-a

Cohen, A. D. (1994). The language used to perform cognitive operations during full-immersion maths tasks. Language Testing, 11(2), 171-195. https://doi.org/10.1177/026553229401100205

Conteh, J. (2018). Translanguaging. ELT Journal, 72(4), 445-447.

Cooper, G. (1998). Research into cognitive load theory and instructional design at UNSW.

Crawford, J. (1998). What now for bilingual education. Rethinking Schools, 13(2), 1.

Creese, A., \& Blackledge, A. (2010). Translanguaging in the bilingual classroom: A pedagogy for learning and teaching?. The modern language journal, 94(1), 103-115.

https://doi.org/10.1111/j.1540-4781.2009.00986.x

Cummins, J. (1979). Linguistic interdependence and the educational development of bilingual children. Review of educational research, 49(2), 222251. https://doi.org/10.3102/00346543049002222

Cummins, J. (1980). The construct of language proficiency in bilingual education. Current issues in bilingual education, 81-103.

Cummins, J. (1981). The role of primary language development in promoting educational success for language minority students. Schooling and language minority students. A theoretical framework.

Cummins, J. (2001). Bilingual children's mother tongue: Why is it important for education.

De Jonge, S., \& Kemp, N. (2012). Text-message abbreviations and language skills in high school and university students. Journal of Research in Reading, 35(1), 49-68. https://doi.org/10.1111/j.1467-9817.2010.01466.x

Duarte, J. (2020). Translanguaging in the context of mainstream multilingual education. International Journal of Multilingualism, 17(2), 232-247. https://doi.org/10.1080/14790718.2018.1512607

Dunkel, P. (1988). The content of L1 and L2 students' lecture notes and its relation to test performance. Tesol Quarterly, 22(2), 259-281. https://doi.org/10.2307/3586936

Faraco, M., Barbier, M. L., \& Piolat, A. (2002). A comparison between note-taking in $\mathrm{L} 1$ and $\mathrm{L} 2$ by undergraduate students. In New Directions for Research in L2 Writing (pp. 145-167). Springer, Dordrecht. https://doi.org/10.1007/978-94-0100363-6_8
Field, A. (2013). Discovering statistics using IBM SPSS statistics. Sage.

García, O. (2009). Education, multilingualism and translanguaging in the 21 st century. In Social justice through multilingual education (pp. 140158). Multilingual Matters. https://doi.org/10.21832/9781847691910-011

García, O. (2011). Educating New York's bilingual children: Constructing a future from the past. International Journal of Bilingual Education and Bilingualism, 14(2), 133-153. https://doi.org/10.1080/13670050.2010.539670

García, O., \& Kano, N. (2014). 11. Translanguaging as Process and Pedagogy: Developing the English Writing of Japanese Students in the US. In The Multilingual Turn in Languages Education (pp. 258-277). Multilingual Matters.

https://doi.org/10.21832/9781783092246-018

García, O., \& Wei, L. (2014). Translanguaging and education. In Translanguaging: Language, bilingualism and education (pp. 63-77). Palgrave Pivot, London.

Goodwin, A. L. (2002). Teacher preparation and the education of immigrant children. Education and urban society, 34(2), 156-172. https://doi.org/10.1177/0013124502034002003

Gopalan, M., Rosinger, K., \& Ahn, J. B. (2020). Use of quasi-experimental research designs in education research: Growth, promise, and challenges. Review of Research in Education, 44(1), 218-243.

https://doi.org/10.3102/0091732x20903302

Günther-van der Meij, M., Duarte, J., \& Nap, L. (2020). Including multiple languages in secondary education: A translanguaging approach. European Journal of Applied Linguistics, 8(1), 73106. https://doi.org/10.1515/eujal-2019-0027

Hamers, J. F. \& Blanc, M. H. (2000). Bilinguality and bilingualism. Cambridge University Press.

Hartley, J. (2002). Note-taking in non-academic settings: A review. Applied Cognitive Psychology: The Official Journal of the Society for Applied Research in Memory and Cognition, 16(5), 559574.

Hesson, S., Seltzer, K., \& Woodley, H. H. (2014). Translanguaging in curriculum and instruction: A CUNY-NYSIEB guide for educators. New York: CUNY-NYSIEB.

Hopp, H., Kieseier, T., Jakisch, J., Sturm, S., \& Thoma, D. (2021). Do minority-language and majority-language students benefit from pedagogical translanguaging in early foreign language development?. Multilingua. https://doi.org/10.1515/multi-2020-0164

Hornberger, N. H., \& Link, H. (2012). Translanguaging and transnational literacies in multilingual classrooms: A biliteracy lens. International Journal of Bilingual Education and Bilingualism, 15(3), 261-278.

https://doi.org/10.1080/13670050.2012.658016

Jacobs, J. (1998, May 14). Latino vote is key to depth 
of 227's victory. One Nation. https://www.onenation.org/opinion/latino-vote-is-key-to-depth-of227-s-victory/.

Kiewra, K. A. (1987). Note-taking and review: The research and its implications. Instructional Science, 16(3), 233-249.

Kiewra, K. A., Benton, S. L., Kim, S. I., Risch, N., \& Christensen, M. (1995). Effects of note-taking format and study technique on recall and relational performance. Contemporary Educational Psychology, 20(2), 172-187.

Kim, H.-Y. (2013). Statistical notes for clinical researchers: Assessing normal distribution (2) using skewness and kurtosis. Restorative Dentistry \& Endodontics, 38(1), 52. https://doi.org/10.5395/rde.2013.38.1.52

Laidlaw, E. N., Skok, R. L., \& McLaughlin, T. F. (1993). The effects of note-taking and self-questioning on quiz performance. Science Education. https://doi.org/10.1002/sce.3730770105

LaVan, C., \& Teacher, F. G. (2001). Help! They're using too much English! The problem of L1 vs. L2 in the immersion classroom. ACIE Newsletter4, 2, 1-4.

Lewis, G., Jones, B., \& Baker, C. (2012). Translanguaging: Origins and development from school to street and beyond. Educational Research and Evaluation, 18(7), 641-654. https://doi.org/10.1080/13803611.2012.718488

Mary, L., \& Young, A. S. (2017). 8. From Silencing to Translanguaging: Turning the Tide to Support Emergent Bilinguals in Transition from Home to Pre-school. In New perspectives on translanguaging and education (pp. 108-128). Multilingual Matters. https://doi.org/10.21832/9781783097821-009

Molnar, A. (2019). SMARTRIQS: A Simple Method Allowing Real-Time Respondent Interaction in Qualtrics Surveys. Journal of Behavioral and Experimental Finance, 22, 161-169. https://doi.org/10.1016/j.jbef.2019.03.005

Park, H. (2019). The effect of L1 and L2 note-taking in academic lecture listening on listening comprehension and analysis of notes.

Piolat, A., Barbier, M. L., \& Roussey, J. Y. (2008). Fluency and cognitive effort during first-and second-language note-taking and writing by undergraduate students. European psychologist, 13(2), 114-125. https://doi.org/10.1027/10169040.13.2.114

Piolat, A., Olive, T., \& Kellogg, R. T. (2005). Cognitive effort during note taking. Applied Cognitive Psychology, 19(3), 291-312. https://doi.org/10.1002/acp.1086

Pratiwi, I. D., \& Marlina, L. (2020). An analysis of abbreviations in twitter status of Hollywood pop singers. English Language and Literature, 9(1). https://doi.org/10.24036/ell.v9i1.108184

Prevoo, M. J., Malda, M., Emmen, R. A., Yeniad, N., \& Mesman, J. (2015). A context-dependent view on the linguistic interdependence hypothesis:
Language use and SES as potential moderators. Language Learning, 65(2), 449-469. https://doi.org/10.1111/lang.12099

Rolstad, K., Mahoney, K., \& Glass, G. V. (2005). The big picture: A meta-analysis of program effectiveness research on English language learners. Educational policy, 19(4), 572-594. https://doi.org/10.1177/0895904805278067

Sakurai, S. (2018). Promoting skills and strategies of lecture listening and note-taking in L2. Fukuoka University Journal of Humanities, 49(4), 10191046.

Saville-Troike, M. (1988). Private speech: Evidence for second language learning strategies during the 'silent' period. Journal of child language, 15(3), 567-590. https://doi.org/10.1017/s0305000900012575

Schulz, K. F., Altman, D. G., Moher, D., Goodman, S., \& Grunberg, S. (2010). CONSORT 2010 Statement Updated Guidelines for Reporting Parallel Group Randomized Trials Background to CONSORT. Mayo Clinic College of Medicine, 115(5), 1097.

https://doi.org/10.1097/AOG.0b013e3181d9d421

Scott, V. M., \& Fuente, M. J. D. L. (2008). What's the problem? L2 learners' use of the L1 during consciousness-raising, form-focused tasks. The Modern language journal, 92(1), 100-1.

https://doi.org/10.1111/j.1540-4781.2008.00689.x

Segaert, K. (2019). Priming effects. Encyclopedia of Personality and Individual Differences, eds $V$. Zeigler-Hill and T. Shackelford (Cham: Springer).

Siegel, J. (2016). A pedagogic cycle for EFL note-taking. ELT Journal, 70(3), 275-286. https://doi.org/10.1093/elt/ccv073

Siegel, J. (2018). Teaching lecture note-taking with authentic materials. ELT Journal, 73(2), 124-133. https://doi.org/10.1093/elt/ccy031

Siegel, J. (2020). Appreciating translanguaging in student notes. ELT Journal, 74(1), 86-88. https://doi.org/10.1093/elt/ccz052

Slavin, R. E., \& Cheung, A. (2005). A synthesis of research on language of reading instruction for English language learners. Review of educational research, 75(2), 247-284.

Swain, M., \& Lapkin, S. (1998). Interaction and second language learning: Two adolescent French immersion students working together. The modern language journal, 82(3), 320-337. https://doi.org/10.1111/j.15404781.1998.tb01209.x

Swain, M., \& Lapkin, S. (2000). Task-based second language learning: The uses of the first language. Language Teaching Research, 4(3), 251274. https://doi.org/10.1191/136216800125087

Sweller, J. (1988). Cognitive load during problem solving: Effects on learning. Cognitive Science, 12(2), 257-285. https://doi.org/10.1207/s15516709cog1202_4

Sweller, J. (2005). Implications of cognitive load 
theory for multimedia learning. The Cambridge handbook of multimedia learning, 3(2), 19-30. https://doi.org/10.1017/cbo9780511816819.003

Sweller, J., Van Merrienboer, J. J., \& Paas, F. G. (1998). Cognitive architecture and instructional design. Educational Psychology Review, 10(3), 251-296.

Suritsky, S. K., \& Hughes, C. A. (1991). Benefits of note-taking: Implications for secondary and postsecondary students with learning disabilities. Learning Disability Quarterly, 14(1), 7-18. https://doi.org/10.2307/1510370

TED-Ed. (2021, March 1). The material that could change the world ... for a third time [Video]. Youtube.

https://www.youtube.com/watch?v=hRI0ymx_6a $\mathrm{w}$

Ticheloven, A. H. L. (2016). Translanguaging as pedagogy in a superdiversity classroom: Constraints and opportunities (Master's thesis).

Tsai-Fu, T. S. A. I., \& Wu, Y. (2010). Effects of notetaking instruction and note-taking languages on college EFL students' listening comprehension. New Horizons in Education, 58(1), 120132.

Vaish, V. (2020). Translanguaging in Multilingual English Classrooms. Springer Singapore. https://doi.org/10.1007/978-981-15-1088-5

Williams, C. (1994). Arfarniad o ddulliau dysgu ac addysgu yng nghyd-destun addysg uwchradd ddwyieithog. Bangor University (United Kingdom).

Williams, J. L., McCarley, N. G., Parker, J., Williams, E. H., Layer, C., \& Walker, D. (2013). The timing of note taking and effects on lecture retention. Delta Journal of Education, 3(2), 92-101. 